\title{
CHARACTERIZATION OF UNYE BENTONITE AFTER TREATMENT WITH SULFURIC ACID
}

\author{
Bulent Caglar \\ Department of Chemistry, Faculty of Science and Arts, Erzincan University, 24100 Erzincan, Turkey \\ Beytullah Afsin* and Engin Koksal \\ Department of Chemistry, Faculty of Science and Arts, Ondokuz Mayis University, 55139 Samsun, Turkey \\ Ahmet Tabak \\ Department of Chemistry, Faculty of Science and Arts, Rize University, 53100 Rize, Turkey \\ Erdal Eren \\ Department of Chemistry, Faculty of Science and Arts, Bilecik University, 11210 Bilecik, Turkey
}

Recebido em 4/9/12; aceito em 25/3/13; publicado na web em 13/6/13

\begin{abstract}
Unye bentonite was found to consist predominantly of a dioctahedral smectite along with quartz, tridymite, cristobalite, and minor fractions of feldspar and anatase. A considerable amount of $\mathrm{Al}$ was retained as a constituent in acid-resistant impurities following the decomposition of the montmorillonite via acid treatment at an acid/clay ratio of 0.4 . These impurities were mesoporous with a maximum surface area of $303.9 \pm 0.4 \mathrm{~m}^{2} \mathrm{~g}^{-1}$. A sharp decrease in the $d_{001}$ lattice spacing of the montmorillonite to $15.33 \AA$ reflected the reduction of the crystallinity in the activated products. In addition, the increase in the ease with which newly formed hydroxyl groups were lost paralleled the severity of the acid treatment.
\end{abstract}

Keywords: acid activation; Unye bentonite; mesoporous.

\section{INTRODUCTION}

Clays comprise the most active fraction of soils, and there are several properties of smectitic clays that make them desirable as catalysts in numerous fields. ${ }^{1,2}$ Acid activation with inorganic acids at elevated temperatures up to $90^{\circ} \mathrm{C}$ is a commonly used process for modifying the physico-chemical properties of clay minerals. ${ }^{3-5}$ The primary uses for acid activated bentonites are waste water treatment, catalysis, industrial, medical, sorption, and environmental remediation or protection applications. ${ }^{6-10}$ However, the microstructural properties of activated clays both determine and limit their potential applications. ${ }^{11-13}$ Thus it is necessary to take into account the mineralogical composition of clay deposits in order to apply acid leaching at an appropriate acid/clay ratio for the preparation of clay products that retain a layered morphology. ${ }^{14-16}$

The most important parameter that determines the catalytic power and adsorption capacity of clay-based materials is the amount of accessible surface area. Altering the total number of micropores and mesopores via acid activation leads to significant changes in the surface area, porosity, and reactivity of the end product and directly influences the adsorptive properties of clays. However, only a part of the clay surface is effectively utilized, and most of the surface does not contribute to the catalytic capacity of the clay. ${ }^{17-19}$ Furthermore, the composition of the smectite layers substantially affects their stability against acid treatment; trioctahedral clays dissolve much faster than their dioctahedral counterparts, and the extent of dissolution of the central atoms from the tetrahedral and octahedral sheets depends on both the clay mineral type and the reaction conditions, such as the acid concentration, time, and temperature of the treatment..$^{20,21}$

The uses of the bentonite deposits in Turkey vary depending on the types and amounts of constituents found, such as smectites, other clay minerals, and non-clay minerals, including quartz, calcite, dolomite, and feldspar. Therefore, there seems to be the need for the careful investigation of the structural properties of these bentonites under

*e-mail: bafsin@omu.edu.tr different conditions in order to be able to use them more efficiently. For example, the current annual production of Unye bentonite in Turkey is estimated to be approximately 45,000 tons, and there is great potential for its utilization in wastewater treatment.

The aim of the present work was to elucidate the structural characteristics of a partly dissolved clay material obtained after the acid treatment of Unye bentonite with sulfuric acid using X-ray fluorescence (XRF), X-ray powder diffraction (XRPD), Fourier transform infrared (FTIR), differential thermal analysis (DTA), thermogravimetric (TG) analysis, and BET specific surface area measurement techniques. Understanding the effect of acid treatment on the structural properties of Unye bentonite, which is currently used as a building material due to its high abundance and low cost, may be of practical importance to environmental engineers and material scientists who wish to design clay-based commercial adsorbents or solid acid catalysts.

\section{EXPERIMENTAL}

\section{Preparation of acid-activated bentonite samples}

Raw Unye bentonite (RB) aliquots ( $2 \mathrm{~g}$ ) that were previously ground and sieved to obtain 38-106 $\mu$ m sized fractions were acid treated with aqueous $\mathrm{H}_{2} \mathrm{SO}_{4}$ (analytical grade) with heating in an oven at $90{ }^{\circ} \mathrm{C}$ for $3 \mathrm{~h}$. The slurries were then cooled down by adding deionized water $(50 \mathrm{ml})$ and the suspension was centrifuged. The leached bentonite powders were repeatedly washed with deionized water until the filtrates were free from sulfate ions and then dried at room temperature, followed by drying at $105^{\circ} \mathrm{C}$ overnight. The series of acid-activated bentonite (AAB) samples thus prepared were labeled as $0.2-\mathrm{AAB}, 0.4-\mathrm{AAB}, 0.6-\mathrm{AAB}, 0.8-\mathrm{AAB}$, and 1.0-AAB according to the acid/clay dry mass ratio (w/w).

\section{Characterization of bentonite samples}

The chemical compositions of the RB and $\mathrm{AAB}$ samples were determined using a Rigaku XRF spectrometer (ZSX100e). The XRPD 
patterns were acquired in the range from 2 to $70^{\circ} 2$ using a Rigaku 2000 diffractometer at $40 \mathrm{kV}$ and $40 \mathrm{~mA}$ with a graphite monochromator and $\mathrm{Cu} \mathrm{K} \alpha$ radiation. The attenuated total reflection (ATR) spectra were recorded on a Bruker Vertex 80v-Fourier transform infrared spectrometer equipped with a DTGS solid-state detector over the spectral range from 4000 to $400 \mathrm{~cm}^{-1}$ at a resolution of 4 $\mathrm{cm}^{-1}$. Thermal analysis runs were carried out on a PYRIS Diamond TG/ DTA apparatus from 20 to $1000{ }^{\circ} \mathrm{C}$ at a heating rate of $10{ }^{\circ} \mathrm{C} /$ min under a nitrogen atmosphere. The amount of sample used in each experiment was $30 \mathrm{mg}$. Calcined $\alpha$-alumina was used as the reference.

Nitrogen adsorption/desorption isotherms were obtained in the relative pressure range from $0.05<\mathrm{P} / \mathrm{P}_{0}<1.00$ using $0.2-0.5 \mathrm{~g}$ of sample with a Micrometrics ASAP 2020 V3.04 H analyzer. The samples were degassed at $150{ }^{\circ} \mathrm{C}$ for $6 \mathrm{~h}$ prior to the measurements at $77 \mathrm{~K}$. Specific surface areas were determined from adsorption isotherms by applying the BET and Langmuir equations ( $\mathrm{S}^{\mathrm{BET}}$ and $\mathrm{S}^{\mathrm{L}}$, respectively). The external surface area $\left(\mathrm{C}_{\mathrm{t}} \mathrm{S}^{\mathrm{Ext}}={ }_{\mathrm{t}} \mathrm{S}^{\mathrm{mp}}\right)$ and micropore area $\left({ }_{\mathrm{t}} \mathrm{S}^{\mu \mathrm{p}}\right)$ were calculated using $t$-plots following the Harkins and Jura equation. Mesoporous surface areas $\left({ }_{\mathrm{BJH}} S^{\mathrm{mp}}\right)$ and volumes $\left({ }_{\mathrm{BJH}} \mathrm{V}^{\mathrm{mp}}\right)$ were determined using the BJH method, while the microporous volumes $\left({ }_{\mathrm{t}} \mathrm{V}^{\mu \mathrm{p}}\right)$ were found via $t$-plots using the Harkins and Jura equation. Pore sizes were represented by both adsorption average pore widths (4V/A from the BET values) and BJH adsorption average pore widths (4V/A), (APW ${ }^{\mathrm{BET}}$ and $\mathrm{APW}^{\mathrm{BJH}}$, respectively). $\mathrm{S}^{\mathrm{sp}}$ is the single point surface area.

\section{RESULTS AND DISCUSSION}

\section{Chemical composition of raw and acid-activated bentonites}

The chemical composition of the RB (wt $\%$ ) is reported in Table 1. The acid treatment resulted in a gradual increase in the amount of $\mathrm{SiO}_{2}$ in the AAB samples at the expense of octahedral cations and tetrahedral $\mathrm{Al}$ from the smectite structure. After an initial decrease in the $\mathrm{CaO}$ and $\mathrm{K}_{2} \mathrm{O}$ content in 0.2-AAB, the amount of these oxides remained constant in the other samples up to 1.0-AAB, reflecting their content in the acid-resistant impurities (e.g., feldspar, cristabolite). The majority of the exchangeable cations and most of the $\mathrm{Fe}$ and $\mathrm{Mg}$ atoms in the octahedral sheet of the 0.2-AAB and 0.4-AAB samples were removed, and thus the relative quantity of $\mathrm{Al}$ atoms increased. The Al contained in the above samples is likely a significant constituent of the insoluble residue. The initial exchange of $\mathrm{H}^{+}$for $\mathrm{Na}$ and $\mathrm{Ca}$ in the interlayer of the bentonite and other minerals and the relative resistance of the feldspar, cristabolite, and tridymite impurities to acid treatment (Table 1) are consistent with previously reported results for non-swelling phyllosilicate layers. ${ }^{18-20}$

\section{XRPD patterns of raw and acid-activated bentonites}

Figure 1 shows the XRPD patterns of the RB and AAB samples. The $d_{001}, d_{003}, d_{020-110}, d_{130-200}$, and $d_{060}$ reflections of the main montmorillonite components were observed at 5.76, 17.60, 19.84, 34.80, and 61.84(20) with the corresponding distances of 15.33, 5.03, 4.47, 2.58 , and $1.50 \AA$, respectively (Figure 1a). ${ }^{18,22}$ The intensity of the $d_{001}$ peak of montmorillonite at $15.33 \AA$ in RB drastically decreased in the diffraction patterns of 0.2-AAB and 0.4-AAB (Figure 1b-c). Meanwhile, the $d_{060}$ peak at $1.50 \AA$, which is typical of dioctahedral smectites, ${ }^{14,23}$ reached a maximum in the $0.4-\mathrm{AAB}$ pattern. The intensity of the $d_{004}$ and $d_{005}$ peaks of montmorillonite, which were seen as combined features with those of tridymite (T) at 3.80 and 2.99 $\AA$, ${ }^{24,25}$ paralleled the weakening of the $\mathrm{d}_{001}$ peak. The simultaneous decrease of the diffraction apexes of the $d_{060}$ and other peaks indicates that no long-range crystallinity was retained at acid/clay ratios above 0.4. (Figure 1d). In addition, the intensities of the $d_{020-110}$ and $d_{130-200}$ reflections of montmorillonite at 4.47 and $2.58 \AA$ decreased nearly to zero with more severe acid treatment (Figure 1e-f)). Furthermore, the peak at $25.27(2 \theta)$, with a distance of $3.51 \AA$, became prominent in the spectrum of $0.8-\mathrm{AAB}$ and reached a maximum intensity in the diffraction pattern of 1.0-AAB (Figure 1(e-f)) subsequent to the release of the octahedral cations. This behavior may be explained by the presence of calcium sulfate, because it is of low solubility in acidic media and its most intense diffraction peak occurs in this $2 \theta$ region. ${ }^{26}$

\section{ATR spectra of raw and acid-activated bentonites}

The ATR spectra of the RB and AAB samples are shown in Figure 2. The intensities of the $\mathrm{OH}$-stretching bands at 3624 and $3614 \mathrm{~cm}^{-1}$ and the hydroxyl bending vibrations at $915 \mathrm{~cm}^{-1}\left(\mathrm{Al}_{2} \mathrm{OH}\right), 885 \mathrm{~cm}^{-1}$ $(\mathrm{AlFeOH})$, and $840 \mathrm{~cm}^{-1}(\mathrm{AlMgOH})$ of $\mathrm{RB}$ (Figure $\left.2 \mathrm{a}\right)^{17,18}$ partially decrease due to the release of $\mathrm{Al}, \mathrm{Fe}$, and $\mathrm{Mg}$ atoms from 0.2-AAB (Figure 2b). The $\mathrm{OH}$-bending band of $\mathrm{AlFeOH}$ disappears completely while the $\mathrm{AlMgOH}$ and $\mathrm{Al}_{2} \mathrm{OH}$ bending bands are barely distinguishable in $0.4-\mathrm{AAB}$. The dissolution of the smectite structure due to the attack of protons on the layers at acid/clay ratios $>0.4$ is highlighted by the weakening and shift to higher wavenumbers by $20-80 \mathrm{~cm}^{-1}$ of the $\mathrm{Si}-\mathrm{O}-\mathrm{Si}$ stretching mode of the tetrahedral sheet, which is located at $986 \mathrm{~cm}^{-1}$ for RB, and the emergence of a quartz band at $794 \mathrm{~cm}^{-1}$.

The medium intensity band seen at $514 \mathrm{~cm}^{-1}$, which is assigned to the lattice Al-Si-O deformation vibration ${ }^{27,28}$ and is likely due to an alumino-silicate structure, is changed to an inflection in the 0.6-AAB sample and then completely vanishes for 0.8 -AAB (Figure $2 \mathrm{~b}-\mathrm{e}$ ) as the result of the depletion of $\mathrm{Al}$ atoms from the octahedral sheet of smectite. The maintenance of this band at $591 \mathrm{~cm}^{-1}$ with a lower intensity in the sample treated with the largest amount of acid (Figure 2f) can be explained by the presence of less soluble impurities, such as feldspar, in the bentonite, which is in agreement with previous studies of dioctahedral smectites. ${ }^{6,13,29}$

\section{Thermal analysis data for the raw and acid-activated bentonites}

The DTA and TG profiles obtained for the RB and AAB samples are reported in Figure 3. The strong endothermic peak centered at $76{ }^{\circ} \mathrm{C}$ with a shoulder at $141{ }^{\circ} \mathrm{C}$ on the DTA curve of the raw clay,

Table 1. The chemical composition of raw and acid-activated bentonites given in wt $\%$ of the metal oxides

\begin{tabular}{cccccccccc}
\hline Sample & $\mathrm{SiO}_{2}$ & $\mathrm{Al}_{2} \mathrm{O}_{3}$ & $\mathrm{MgO}$ & $\mathrm{Fe}_{2} \mathrm{O}_{3}$ & $\mathrm{CaO}$ & $\mathrm{K}_{2} \mathrm{O}$ & $\mathrm{TiO}_{2}$ & $\mathrm{Na}_{2} \mathrm{O}$ \\
\hline $\mathrm{RB}$ & 62.87 & 24.37 & 5.77 & 2.48 & 2.08 & 1.85 & 0.22 & 0.21 \\
$0.2-\mathrm{AAB}$ & 76.75 & 15.09 & 2.94 & 1.72 & 1.30 & 1.79 & 0.23 & 0.09 \\
$0.4-\mathrm{AAB}$ & 80.14 & 12.01 & 2.10 & 1.43 & 1.92 & 1.97 & 0.29 & 0.04 \\
$0.6-\mathrm{AAB}$ & 86.17 & 7.64 & 1.42 & 0.73 & 1.99 & 1.75 & 0.20 & 0.03 \\
$0.8-\mathrm{AAB}$ & 89.94 & 4.25 & 0.50 & 0.36 & 1.90 & 1.80 & 0.12 & --- \\
$1.0-\mathrm{AAB}$ & 94.00 & 1.96 & 0.30 & 0.03 & 1.83 & 1.74 & 0.10 & --- \\
\hline
\end{tabular}




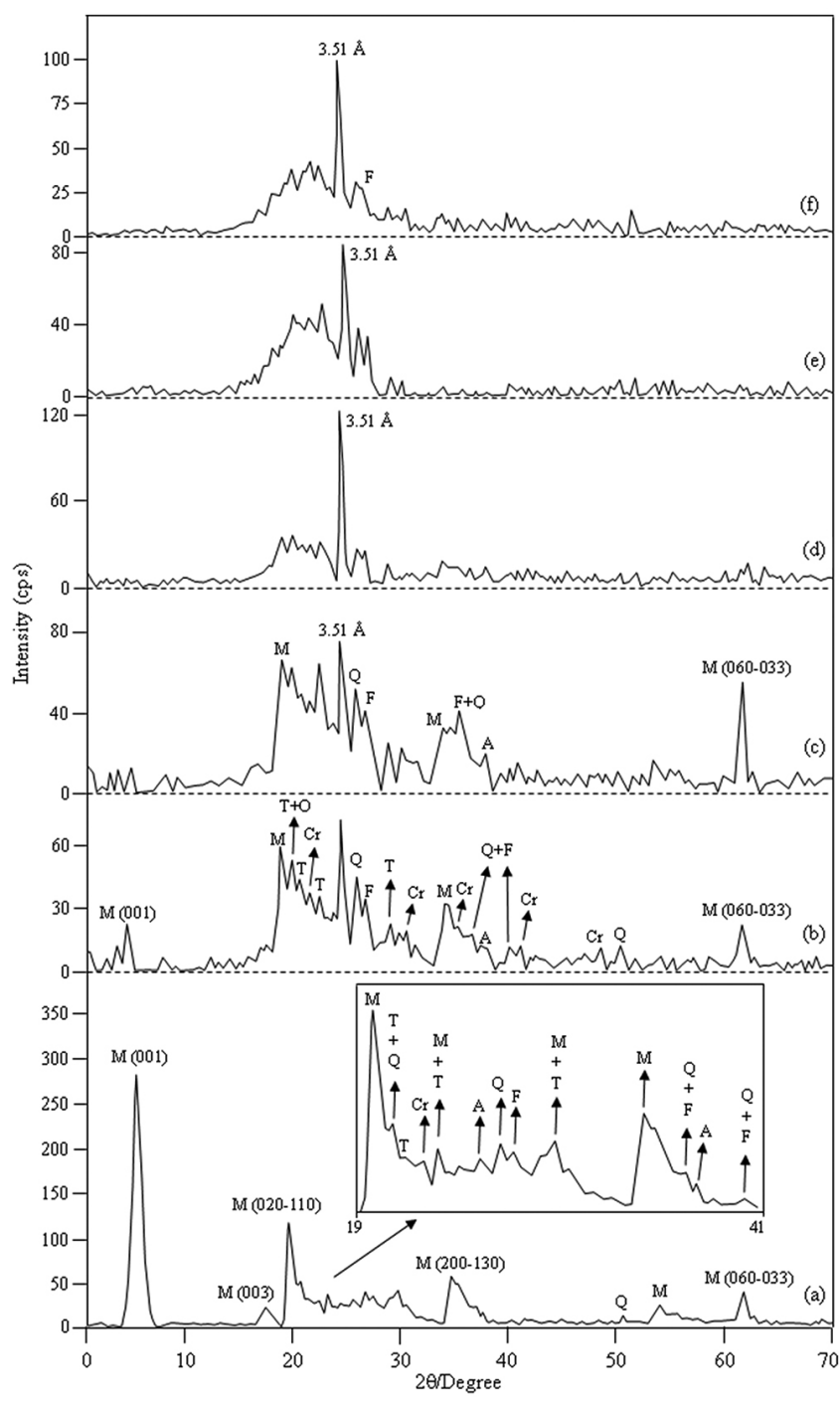

Figure 1. XRPD patterns of the bentonite samples (a) $R B$, (b) 0.2-AAB, (c) 0.4-AAB, (d) 0.6-AAB, (e) 0.8-AAB, and (f) 1.0-AAB

which was accompanied by a mass loss of $8.50 \%$ between 30 and $220{ }^{\circ} \mathrm{C}$ (Figure $3 \mathrm{a}$ ), corresponds to the desorption of weakly adsorbed interlayer water molecules..$^{22,30}$ Dehydroxylation occurs in the temperature range from 220 to $750{ }^{\circ} \mathrm{C}$ with a maximum rate at 636 ${ }^{\circ} \mathrm{C}$. In $0.2-\mathrm{AAB}$, the reaction occurring in the range from 321 to 661 ${ }^{\circ} \mathrm{C}$ with a maximum at $590{ }^{\circ} \mathrm{C}$ (a mass loss of $2.90 \%$ ) indicates the dehydroxylation of $\mathrm{Si}-\mathrm{OH}$ and $\mathrm{Al}-\mathrm{OH}$ groups that were newly formed as a result of the partial rupture and disorder of the tetrahedral and octahedral sheets. This dehydroxylation takes place at lower temperatures than in the RB sample (Figure $3 b$ ). ${ }^{11,27}$

The mass loss of $2.90 \%$ in the range from 640 to $999^{\circ} \mathrm{C}$ in $0.6-$ $\mathrm{AAB}$ is accompanied by the removal of the structural $\mathrm{OH}$ groups of the alumino-silicate phase at $720^{\circ} \mathrm{C}$ (Figure $3 \mathrm{~d}$ ), which is observed with smectites ${ }^{17,18}$ and montmorillonite. ${ }^{3}$ The dehydroxylation reaction in 0.8 - AAB is centered at $549{ }^{\circ} \mathrm{C}$ (Figure 3e), whereas the endothermic peaks for $1.0-\mathrm{AAB}$ appear at 311 and $519{ }^{\circ} \mathrm{C}$ with a mass loss of $3.60 \%$ over a wider temperature range $\left(280-895^{\circ} \mathrm{C}\right)$ (Figure 3f). The reactions associated with the dehydroxylation of the octahedral sheet occur at different temperatures depending on the acid/clay ratio, and the reactions (e.g., at 406 and $311^{\circ} \mathrm{C}$ in Figure $3 \mathrm{c}$ and $3 \mathrm{f}$, respectively) are related to the thermal decomposition of the phases (e.g., Fe-, Al-hydroxyl) that are formed as a result of the acid leaching treatment. Thus, the total mass loss in

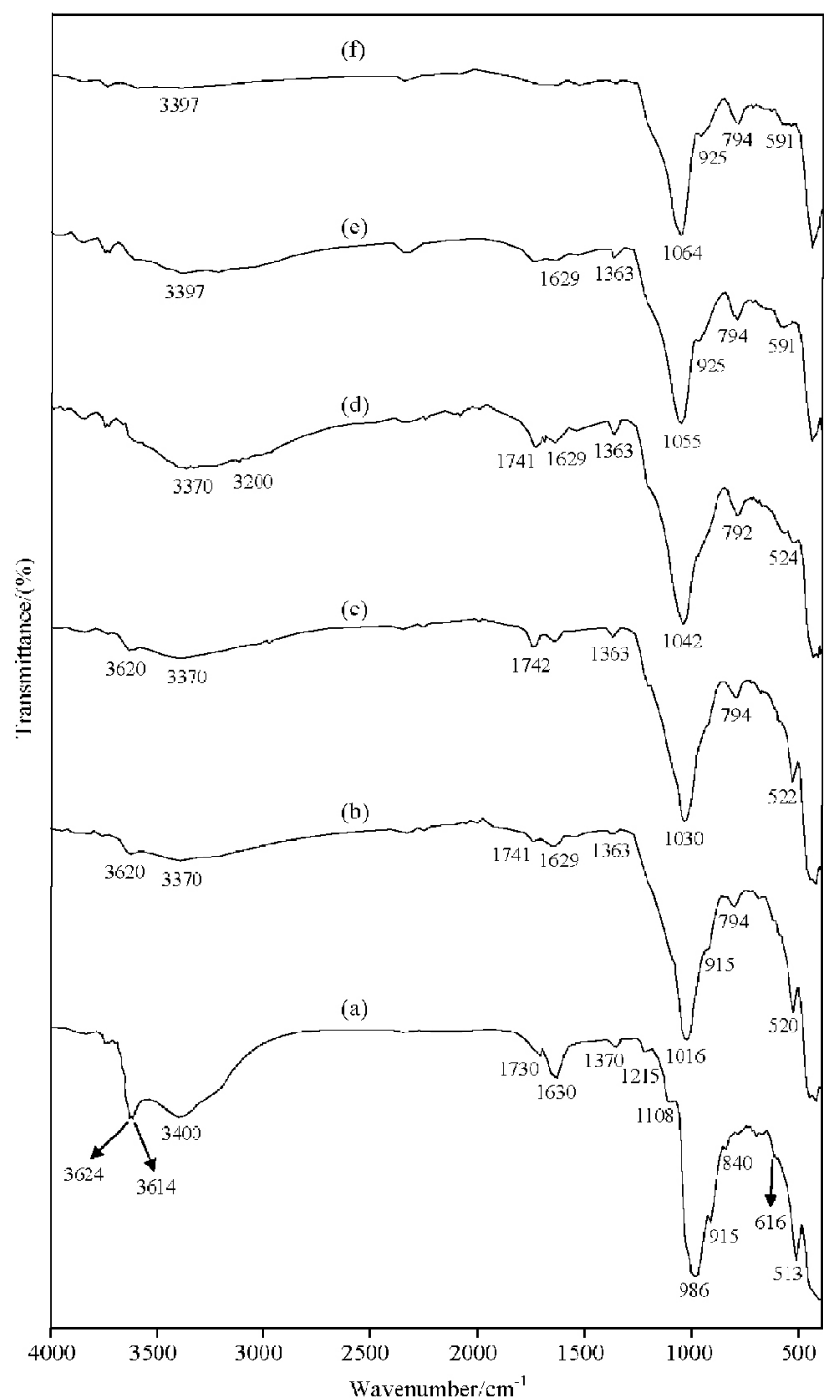

Figure 2. ATR spectra of the bentonite samples (a) RB, (b) 0.2-AAB, (c) 0.4$A A B,(d) 0.6-A A B,(e) 0.8-A A B$, and (f) 1.0-AAB

the activated samples paralleled the severity of the acid treatment, and the dehydroxylation temperature decreased with an increase in the acid/clay ratio (Figure 3b-f); this feature may be explained by the easier loss of the hydroxyl units from the broken edges of the mechanically deformed bentonites. ${ }^{14,31,32}$

\section{Surface area measurements of raw and acid-activated bentonites}

The specific surface area of raw bentonite $\left(61.1 \pm 0.9 \mathrm{~m}^{2} / \mathrm{g}\right)$, which constitutes the microporous $\left(20.2 \pm 0.3 \mathrm{~m}^{2} / \mathrm{g}\right)$ and mesoporous $\left(40.9 \pm 0.6 \mathrm{~m}^{2} / \mathrm{g}\right)$ contributions, increased by $c a$. 5 -fold for $0.2-\mathrm{AAB}$ $\left(298.0 \pm 0.4 \mathrm{~m}^{2} / \mathrm{g}\right)$; the microporous volume $\left(0.0107 \mathrm{~cm}^{3} / \mathrm{g}\right)$ disappeared completely while the mesoporous volume $\left(0.1077 \mathrm{~cm}^{3} / \mathrm{g}\right)$ reached a value of $0.3389 \mathrm{~cm}^{3} / \mathrm{g}$ (Table 2). The increase in the number of mesopores may be interpreted as an outcome of the removal of metal cations from the octahedral sheet..$^{21,31}$ The increase in the surface area results from the initial replacement of exchangeable cations by protons, which is followed by the extraction of $\mathrm{Al}, \mathrm{Fe}$, and $\mathrm{Mg}$ atoms from octahedral and tetrahedral sites. ${ }^{13,14,32}$ Both the mesoporous volume $\left(0.4023 \mathrm{~cm}^{3} / \mathrm{g}\right)$ and the mesoporous area $\left(299.7 \pm 0.4 \mathrm{~m}^{2} / \mathrm{g}\right)$ reached a maximum for $0.4-\mathrm{AAB}$, because the vacancies that occurred 
in the octahedral sheet led to a further increase in the number of mesopores. RB has an average pore width of $10.45 \mathrm{~nm}$, whereas the

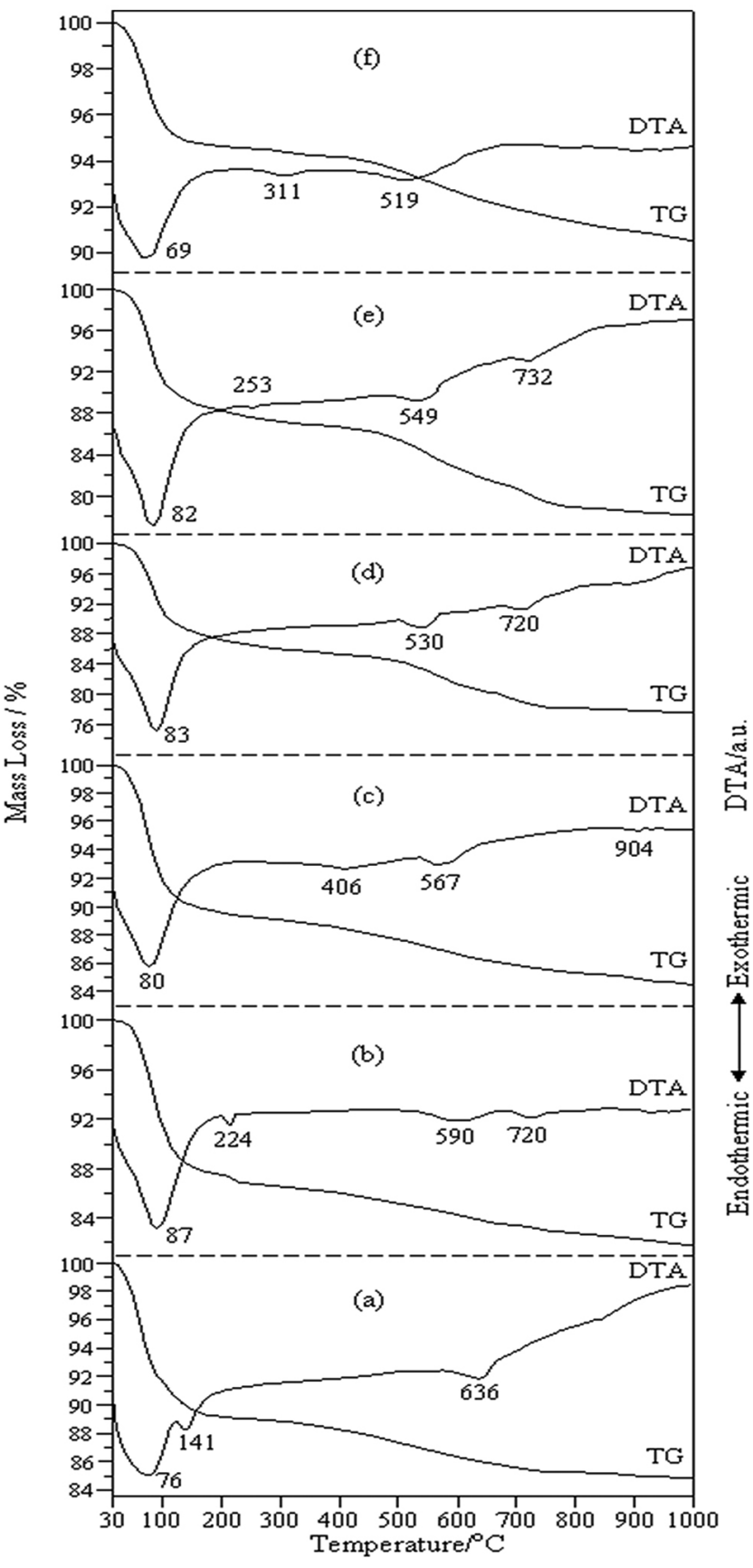

Figure 3. DTA and TG curves of the bentonite samples (a) RB, (b) 0.2-AAB, (c) 0.4-AAB, (d) 0.6-AAB, (e) 0.8-AAB, and (f) 1.0-AAB value of this parameter fell in the range from $4.38-4.83 \mathrm{~nm}$ for the $0.2-\mathrm{AAB}$ and $0.4-\mathrm{AAB}$ samples. However, the central $\mathrm{Al}^{3+}$ cations in the latter sample were removed without completely destroying the octahedral sheet.

The reduction of the specific surface area to $182.7 \pm 0.8 \mathrm{~m}^{2} / \mathrm{g}$ for $0.6-\mathrm{AAB}$ may be ascribed to the change in the porosity distribution. Implicit in the above trend is the fact that the partial destruction of the smectite structure gave rise to the growth of an alumino-silicate phase as the result of the cross-linking of the residual tetrahedral sheets. ${ }^{17,20}$ Thereafter, a similar trend continued with further activation in line with the acid/clay ratio, and the influence of the free silica became more important, yielding even a smaller specific surface area $\left(168.8 \pm 0.9 \mathrm{~m}^{2} / \mathrm{g}\right)$ in $0.8-\mathrm{AAB}$. The decrease in the specific surface area also reflected the fact that the acid treatment dissolved the impurities and reduced the effect of the enlarged radii of the mesopores in which the protons could easily open the edges of the platelets and expand the pore diameter. ${ }^{11,27}$ In contrast, the removal of the metal cations from the octahedral sheet of 1.0-AAB caused an increase in the number of both the micropores and the mesopores again, and therefore the surface area of this sample was found to be $208.1 \pm 1.3 \mathrm{~m}^{2} / \mathrm{g}$.

\section{CONCLUSIONS}

Treatment of Unye bentonite with increasing amounts of sulfuric acid led to the gradual removal of $\mathrm{Al}, \mathrm{Fe}$, and $\mathrm{Mg}$ atoms from the octahedral sheet, which was accompanied by typical changes in the structural characteristics. The acid treatment first leached metal ions from the clay mineral lattice and then introduced mesoporosity. The maximum surface area $\left(303.9 \pm 0.4 \mathrm{~m}^{2} / \mathrm{g}\right)$ was achieved at an acid/clay (w/w) ratio of 0.4 and was linked to the variation in the mesopore size subsequent to the partial elimination of the octahedral cations. The partially dissolved materials in the fine fractions of the bentonites examined in the present study were mainly mesoporous with an average pore width in the range from 4 to $12 \mathrm{~nm}$. The intermediate microporous structure gradually became mesoporous as the dissolution progressed in an increasingly proton-rich environment, and the discernible intensities for the cristobalite, tridymite, and feldspar reflections in the diffraction patterns of the acid-activated samples provided evidence that the non-clay constituents remained as acid-insoluble admixtures. The lower departure temperature of the hydroxyl groups from the smectite structures after depletion of the octahedral sheets was confirmed by the endothermic peaks on the thermo diagrams. Based on these results, it can be concluded that Unye bentonite activated with different acid concentrations may be used as a precursor for the preparation of clay heterostructures with a high fraction of mesopores. The data presented in this study may also provide further insight into catalysis studies and conversion processes, as well as for the application of clay science in the growing field of environmental management.

Table 2. Structure parameters of raw and acid-activated bentonites

\begin{tabular}{|c|c|c|c|c|c|c|c|c|c|c|c|}
\hline Sample & $\begin{array}{c}\mathrm{S}^{\mathrm{BET}} \\
\left(\mathrm{m}^{2} \mathrm{~g}^{-1}\right) \\
\end{array}$ & $\begin{array}{c}\mathrm{S}^{\mathrm{L}} \\
\left(\mathrm{m}^{2} \mathrm{~g}^{-1}\right) \\
\end{array}$ & $\begin{array}{c}\mathrm{S}^{\mathrm{sp}} \\
\left(\mathrm{m}^{2} \mathrm{~g}^{-1}\right) \\
\end{array}$ & 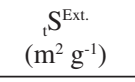 & 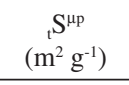 & $\underset{\substack{\mathrm{t} \\
\left(\mathrm{m}^{2} \mathrm{~g}^{-1}\right)}}{\mathrm{m}^{-1}}$ & $\begin{array}{c}{ }^{\text {BJHH }} S^{m p} \\
\left(m^{2} g^{-1}\right)\end{array}$ & $\begin{array}{c}\mathrm{V}^{\mu \mathrm{p}} \\
\left(\mathrm{cm}^{3} \mathrm{~g}^{-1}\right)\end{array}$ & $\begin{array}{c}\mathrm{V}^{\mathrm{mp}} \\
\left(\mathrm{cm}^{3} \mathrm{~g}^{-1}\right)\end{array}$ & $\begin{array}{l}\mathrm{APW}^{\mathrm{BET}} \\
(\mathrm{nm})\end{array}$ & $\begin{array}{c}\mathrm{APW}^{\mathrm{BJH}} \\
(\mathrm{nm})\end{array}$ \\
\hline $\mathrm{RB}$ & $611+09$ & $931+16$ & $8+09$ & $409+06$ & $20.2 \pm 0.3$ & $409+06$ & $41.2 \pm 0.6$ & 0.0107 & 0.1077 & 7.16 & 10.45 \\
\hline $0.2-\mathrm{AAB}$ & $298.0 \pm 0.4$ & $459.4 \pm 15.3$ & $290.8 \pm 0.4$ & $298.8 \pm 0.4$ & ---- & $298.8 \pm 0.4$ & $309.6 \pm 0.5$ & ---- & 0.3389 & 4.54 & 4.38 \\
\hline $0.4-\mathrm{AAB}$ & $303.9 \pm 0.4$ & $468.3 \pm 15.6$ & $297.1 \pm 0.4$ & $299.7 \pm 0.4$ & $4.3 \pm 0.0$ & $299.7 \pm 0.4$ & $333.5 \pm 0.4$ & ---- & 0.4023 & 5.25 & 4.83 \\
\hline $0.6-\mathrm{AAB}$ & $182.7 \pm 0.8$ & $280.3 \pm 8.1$ & $178.3 \pm 0.8$ & $170.6 \pm 0.7$ & $12.1 \pm 0.0$ & $170.6 \pm 0.7$ & $203.5 \pm 0.9$ & 0.00489 & 0.358 & 7.80 & 7.03 \\
\hline $0.8-\mathrm{AAB}$ & $168.8 \pm 0.9$ & $258.8 \pm 7.1$ & $164.4 \pm 0.9$ & $155.8 \pm 0.9$ & $13.03 \pm 0.1$ & $155.8 \pm 0.9$ & $188.3 \pm 1.0$ & 0.00543 & 0.505 & 11.70 & 10.72 \\
\hline 1.0-AAB & $208.1 \pm 1.3$ & $319.6 \pm 8.3$ & $203.0 \pm 1.3$ & $188.4 \pm 1.1$ & $19.7 \pm 0.1$ & $188.4 \pm 1.2$ & $243.1 \pm 1.5$ & 0.00864 & 0.637 & 12.10 & 10.48 \\
\hline
\end{tabular}




\section{ACKNOWLEDGMENTS}

This work was supported by the Research Foundation of Ondokuz Mayis University under Project No. F467.

\section{REFERENCES}

1. Pichowicz, M.; Mokaya, R.; Chem. Commun. 2001, 20, 2100.

2. Mikhail, S.; Zaki, T.; Khalil, L.; Appl. Catal. A-Gen. 2002, 227, 265.

3. Noyan, H.; Önal, M.; Sarıkaya, Y.; J. Therm. Anal. Calorim. 2008, 94, 591.

4. Sakizci, M.; Alver, B. E.; Alver, O.; Yorukogullari, E.; J. Mol. Struct. 2010, 969, 187.

4. Koksal, E.; Afsin, B.; Tabak, A.; Caglar, B.; Spectrosc. Lett. 2011, 44 77.

6. Janek, M.; Lagaly, G.; Appl. Clay Sci. 2001, 19, 121.

7. Wu, P. X.; Liao, Z. W.; Zhang, H. F.; Guo, J. G.; Environ. Int. 2001, 26, 401 .

8. Villar, M. V.; García-Siñeriz, J. L.; Bárcena, I.; Lloret, A.; Eng. Geol. 2005, 80, 175 .

9. Volzone C.; Ortiga, J.; Appl. Clay Sci. 2009, 44, 251.

10. Rossetto, E.; Beraldin, R.; Penha, F. G.; Pergher, S. B. C.; Quim. Nova 2009, 32, 2064.

11. Dékány, I.; Turi, L.; Fonseca, A.; Nagy, J. B.; Appl. Clay Sci. 1999, 14, 141.

12. Melo, D. M. A.; Ruiz, J. A. C.; Melo, M. A. F.; Sobrinho, E. V.; Schmall, M.; Microporous Mesoporous Mater. 2000, 38, 345.

13. He, H.; Guo, J.; Xie, X.; Lin, H.; Li, Y.; Clay Miner. 2002, 37, 337.

14. Srasra, E.; Bergaya, F.; Van Damme, H.; Ariguib, N. K.; Appl. Clay Sci. 1989, 4, 411.

15. Xi, Y. F.; Ding, Z.; He, H. P.; Frost, R. L.; J. Colloid Interf. Sci. 2004, $277,116$.
16. Nguetnkam, J. P.; Kamga, R.; Villiéras, F.; Ekodeck, G. E.; Razafitianamaharavo, A.; Yvon, J.; Appl. Clay Sci. 2011, 52, 122.

17. Rodriguez, M. A. V.; Barrios, M. S.; Gonzalez, J. D. L.; Munoz, M. A. B.; Clays Clay Miner. 1994, 42, 724.

18. Christidis, G. E.; Scott, P. W.; Dunham, A. C.; Appl. Clay Sci. 1997, 12, 329.

19. Flessner, U.; Jones, D. J.; Roziere, J.; Zajac, J.; Storaro, L.; Lenarda, M.; Pavan, M.; Lopez, A. J.; Castellon, E. R.; Trombetta, M.; Busca, G.; J. Mol. Catal. A: Chem. 2001, 168, 247.

20. Steudel, A.; Batenburg, L. F.; Fischer, H. R.; Weidler, P. G.; Emmerich, K.; Appl. Clay Sci. 2009, 44, 105.

21. Neumann, A.; Petit, S.; Hofstetter, T. B.; Geochim. Cosmochim. Acta 2011, 75, 2336.

22. Caglar, B.; Afsin, B.; Tabak, A.; Eren, E.; Chem. Eng. J. 2009, 149, 242.

23. Korichi, S.; Elias, A.; Mefti, A.; Appl. Clay Sci. 2009, 42, 432.

24. Güven, N.; Grim, R. E.; Clays Clay Miner. 1972, 20, 89.

25. Dananaj, I.; Frankovská, J.; Janotka, I.; Appl. Clay Sci. 2005, $28,223$.

26. Twomey, C.; Birkinshaw, C.; Breen, S.; J. Chem. Technol. Biotechnol. 2004, 79, 486.

27. Tomić, Z. P.; Logar, V. P.; Babic, B. M.; Rogan, J. R.; Makreski, P.; Spectrochim. Acta, Part A 2011, 82, 389.

28. Madejová, J.; Komadel, P.; Clays Clay Miner. 2001, 49, 410.

29. Gates, W. P.; Anderson, J. S.; Raven, M. D.; Churchman, G. J.; Appl. Clay Sci. 2002, 20, 189.

30. Tabak, A.; Afsin, B.; Caglar, B.; Koksal, E.; J. Colloid Interface Sci. 2007, 313, 5 .

31. Temuujin, J.; Jadambaa, Ts.; Burmaa, G.; Erdenechimeg, Sh.; Amarsanaa, J.; MacKenzie, K. J. D.; Ceram. Int. 2004, 30, 251.

32. Dellisanti, F.; Valdré, G.; Appl. Clay Sci. 2005, 28, 233. 